\title{
Choice of place for childbirth: prevalence and correlates of utilization of health facilities in Chongwe district, Zambia
}

\author{
"Hazemba AN, Siziya S \\ Department of Community Medicine, School of Medicine, University of Zambia.
}

\begin{abstract}
Objectives: To determine the prevalence and correlates for utilization of health facilities for childbirth in a rural Chongwe district, Zambia.
\end{abstract}

Design: A cross sectional study was carried among 250 mothers who had delivered babies within one year prior to the survey. A Backward multiple logistic regression method was used to determine independent predictors for utilization of health services for childbirth.

Main Outcome Measures: Percent utilization of health facilities.

Results: A total of 250 mothers were recruited into the study, of whom the majority were below the age of 25 year $(41.2 \%)$ and were married $(84.0 \%)$. A third (32.8\%) of the mothers were not able to read and write. The rate of health facility utilisation for childbirth was $42.8 \%$. Independent predictors for utilisation of a health facility were place of last childbirth, and knowledge that traditional birth attendants (TBAs) are given none food items (excluding money) after assisting delivery. Compared to mothers who delivered their last pregnancy at a health facility, mothers who had their last childbirth at home were $85 \%(\mathrm{AOR}=0.15,95 \% \mathrm{CI}[0.10,0.22])$ less likely to deliver their current pregnancy at a health facility. Knowledge that a TBA was given none food items (excluding money) after assisting delivery was negatively associated with delivery at a health facility $(\mathrm{AOR}=0.55,95 \% \mathrm{CI}[0.37,0.83])$.

Conclusion: The importance of giving birth at a health facility should be communicated to mothers who give birth at home, during postnatal visits or clinic outreach sessions.

\footnotetext{
"Corresponding author:

Alice Ngoma Hazemba

Department of Community Medicine

School of Medicine

University of Zambia

P O Box 50110

Lusaka, Zambia
}

\section{INTRODUCTION}

Zambia adopted the concept of Primary Health Care (PHC) to bring health services including maternity services as close to the family as possible. It is estimated that $50 \%$ of households in rural areas are within a radius of $5 \mathrm{~km}$ from a health facility ${ }^{1}$. In spite of the closeness to a health facility, only $27.9 \%$ of live births were delivered at such health facilities ${ }^{2}$, suggesting that $22.1 \%$ of the expectant women did not deliver at a health facility despite being within reach of a health facility. There is overwhelming evidence that distance to a health facility is a strong determinant of the choice for maternal health services $^{3,4}$, However, factors other than distance to health facility have been reported to be associated with health service utilization for childbirth such as education $^{5-8}$, maternal age ${ }^{3,6}$, parity ${ }^{6,8}$, economic status ${ }^{7}$, cultural factors and beliefs, lack of skilled staff at primary health care level, and health worker negative attitudes towards expectant mothers ${ }^{9}$.

Provision of safe motherhood is of utmost importance in the reduction of maternal mortality. Zambia has one of the highest maternal mortality rate in the world at $729 / 100000$ live births ${ }^{2}$, and can be as high as 1300 / 100000 live births in some remote areas ${ }^{10}$. Safe deliveries can only be guaranteed if deliveries are conducted at a health facility by skilled staff. However, staffing of qualified staff for safe deliveries in health facilities in Zambia remains a challenge. Overall, 33\% of rural health centres are staffed by unqualified health workers ${ }^{11}$, and the shortage of midwives is even more critical.

While the ZDHS 2001-2002 ${ }^{2}$ provides rates of deliveries conducted at health facilities by background characteristics (maternal age, birth order, residence, province, mother's education, and antenatal care visits), there is scanty information on the factors associated with utilization of health facilities for childbirth. Furthermore, parity, place of delivery of last child, and 
traditional birth attendants-related factors were not examined in this report. We, therefore, conducted this study to determine factors associated with the utilization of health facilities for childbirth in a rural setting of Chongwe district in Zambia. Due to varying rates of utilization of health facilities for child birth between rural areas, we also aimed to estimate this prevalence in a rural district closest to the capital city, Lusaka, of Zambia.

\section{METHODS}

\section{Study Design}

A cross-sectional study was conducted to collect information on the study factors.

\section{Study site}

The description of the study site is given elsewhere ${ }^{12}$ but in brief Chongwe had a ratio of 1 midwife to 1,063 women in a population of 145,000 people of whom 31,900 were women in the reproductive age range 1549 years.

\section{Study population, Sample size, and sampling}

Mothers in the reproductive age group of 15-49 years, having delivered six months prior to data collection and attending children's clinic were requested to take part in the study.

Out of the total population of 145,000 (Chongwe District Health Information System report, 2000) people in the district, $4 \%$ were children aged less than one year, giving a total of 5800 children. Therefore in a month it was estimated that there would be 483 children under the age of one year. Using a Statcalc programme in Epi Info version 6 , with this population size, assuming expected frequency of $50 \% \pm 5 \%$ and a $95 \%$ confidence level, the required minimum sample size was 217 . Furthermore, with a 95\% response rate the adjusted minimum sample size was 225 .

The first 13 mothers attending children's clinic on the day of data collection from each of the 24 health facilities were selected. However, 4 health facilities were not reached, and in some health facilities only a few mothers attended the children's clinic, thus reducing the sample size.

\section{Data collection techniques}

Structured questionnaires were used for interviews. Both closed and open-ended questions were utilised for collecting data. The questionnaire included items on socioeconomic characteristics; obstetric factors, decision making, place delivery of last child, and traditional birth attendants-related factors

\section{Data processing and analysis}

Filled-in questionnaires were checked for completeness and consistency of the responses. Open ended questions were post-coded and entered on the questionnaire. Data entry was done using Epi Info version 6. Further, editing of the data occurred after data entry by running frequencies and checking for out of range responses. Preliminary analysis was done in Epi Info version 6 as well. The Yates' corrected Chi-squared test was used to determine associations between predictor variables and the outcome, and the Yates corrected Chi-squared test was not valid, the Fisher's exact test was used. Meanwhile the Backward logistic regression was used to determine independent predictors for utilization of health services for childbirth. Adjusted Odds ratios (AOR) are reported together with their $95 \%$ confidence intervals $(\mathrm{CI})$.

\section{Ethical considerations}

The protocol was reviewed and approved by the by University of Zambia, Research Ethics Committee. Permission to conduct the study was sought from the Chongwe district Director of Health. All respondents consented before participating in the study.

\section{RESULTS}

\section{Sample description}

Overall, 250 mothers participated in the survey. The majority, 103 (41.2\%) were of age less than 25 years, 89 $(35.6 \%)$ were aged $25-34$ years, and 58 (23.2\%) were of age 35 years or more. In terms of the marital status of the participants, $40(16.0 \%)$ were single, and 210 $(84.0 \%)$ were married. Most, 227 (90.8\%), of the participants were house wives, and only $23(9.2 \%)$ were employed. About a third, $80(32.8 \%)$, of the participants were not able to read and write, while $170(68.0 \%)$ were able to do so. The rate of utilization of a health facility for childbirth was $42.8 \%$. 


\section{Bivariate analyses}

Table 1 shows socio-demographic correlates for choice of place of childbirth. Ability to read and write was positively associated with utilization of health facility for child birth (AOR=2.23, 95\% CI [1.23, 4.11]). Parity was also significantly associated with choice of health facility for childbirth (Table 2). Compared with mothers who had 3 or more children, mothers who had one child were $92 \%$ (AOR=1.92, 95\%CI [1.01, 3.67]) more likely to deliver at a health facility. Mothers who had their last pregnancy delivered at home were $97 \%(\mathrm{AOR}=0.03$, $95 \% \mathrm{CI}[0.01,0.06)]$ ) less likely to utilize health facilities for their current childbirth compared to mothers who had delivered their last pregnancy at a health facility. Mothers who thought that there were more women delivered by traditional birth attendants were $42 \%$ $(\mathrm{AOR}=0.58,95 \% \mathrm{CI}[0.34,0.99])$ less likely to deliver at a health facility compared to mothers who thought otherwise (Table 3 ).

Table 1. Socio-demographic correlates for choice of place of childbirth

\begin{tabular}{|c|c|c|c|}
\hline Factor & $\begin{array}{l}\text { Health Fa } \\
\text { Delivery } \\
\mathrm{n}(\%)\end{array}$ & $\begin{array}{l}y \text { Home } \\
\text { delivery } \\
\mathrm{n}(\%)\end{array}$ & $\mathrm{p}$ value \\
\hline \multicolumn{4}{|l|}{ Age } \\
\hline$<25$ & $51(47.7)$ & $52(36.4)$ & 0.199 \\
\hline $25-34$ & $34(31.8)$ & $55(38.5)$ & \\
\hline $35+$ & $22(20.6)$ & $36(25.2)$ & \\
\hline \multicolumn{4}{|c|}{ Marital Status } \\
\hline Single & $21(19.6)$ & $19(13.3)$ & 0.239 \\
\hline Married & $86(80.4)$ & $124(86.7)$ & \\
\hline \multicolumn{4}{|l|}{ Occupation } \\
\hline House Wife & $95(88.8)$ & $132(92.3)$ & 0.464 \\
\hline Employed & $12(11.2)$ & $11(7.7)$ & \\
\hline \multicolumn{4}{|c|}{ Able to read and write } \\
\hline Yes & $83(77.6)$ & $87(60.8)$ & 0.008 \\
\hline No & $24(22.4)$ & $56(39.2)$ & \\
\hline
\end{tabular}

Table 2. Obstetric correlates for choice of place for childbirth

\begin{tabular}{|c|c|c|c|}
\hline Factor & $\begin{array}{l}\text { Health Facility } \\
\text { Delivery } \\
\mathrm{n}(\%)\end{array}$ & $\begin{array}{l}\text { y } \begin{array}{l}\text { Home } \\
\text { delivery }\end{array} \\
\mathrm{n}(\%)\end{array}$ & $\mathrm{p}$ value \\
\hline \multicolumn{4}{|c|}{ Number of children } \\
\hline 1 & $52(48.6)$ & $46(32.2)$ & 0.030 \\
\hline 2 & $25(23.4)$ & $46(32.2)$ & \\
\hline $3+$ & $30(28.0)$ & $51(35.7)$ & \\
\hline \multicolumn{4}{|c|}{$\begin{array}{l}\text { Decided on choice of } \\
\text { place for delivery }\end{array}$} \\
\hline Self & $67(62.6)$ & $97(67.8)$ & 0.358 \\
\hline Husband & $29(27.1)$ & $28(19.6)$ & \\
\hline Other & $11(10.3)$ & $18(12.6)$ & \\
\hline \multicolumn{4}{|c|}{ Place of delivery of last child } \\
\hline Home & $18(16.8)$ & $125(87.4)$ & $<0.001$ \\
\hline Health facility & $89(83.2)$ & $18(12.6)$ & \\
\hline
\end{tabular}

Table 3. Traditional birth attendants knowledge-related correlates for choice of place for childbirth

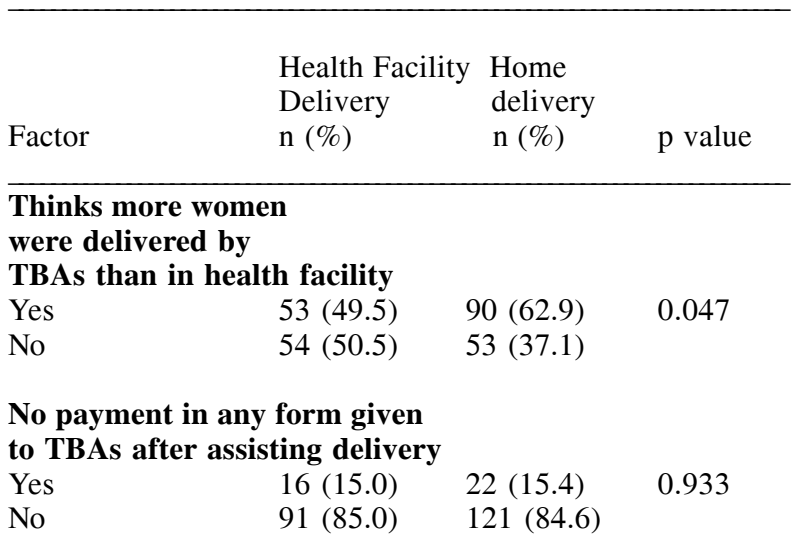

Money given to TBA after assisting delivery

$\begin{array}{llll}\text { Yes } & 48(44.9) & 79(55.2) & 0.134 \\ \text { No } & 59(55.1) & 64(44.8) & \end{array}$

Food given to TBA after assisting delivery

$\begin{array}{llll}\text { Yes } & 42(39.3) & 42(29.4) & 0.133 \\ \text { No } & 101(70.6) & 65(60.7) & \end{array}$

None food items (excluding money) given to TBAs after assisting delivery

$\begin{array}{llll}\text { Yes } & 45(42.1) & 76(53.1) & 0.108\end{array}$

TBAs offered delivery services

$\begin{array}{llll}\text { Yes } & 100(93.5) & 139(97.2) & 0.213 \\ \text { No } & 7(6.5) & 4(2.8) & \end{array}$

TBAs offered PNC

$\begin{array}{llll}\text { Yes } & 12(11.2) & 19(13.3) & 0.766 \\ \text { No } & 95(88.8) & 124(86.7) & \end{array}$




\section{Multivariate analysis}

Of the factors considered in bivariate analysis, only place of delivery of last child, and giving traditional birth attendants non food items (excluding money) after assisting a delivery were significantly associated with choice of place for childbirth. Compared to mothers who delivered their last pregnancy at a health facility, mothers who had their last childbirth at home were $85 \%$ $(\mathrm{OR}=0.15,95 \% \mathrm{CI}[0.10,0.22])$ less likely to deliver their current pregnancy at a health facility. Mothers who stated that a traditional birth attendant was given none food items (excluding money) after assisting a delivery were $45 \%$ (OR=0.55, 95\% CI [0.37, 0.83]) less likely to deliver at a health facility compared to mothers who stated otherwise.

\section{DISCUSSION}

We found a rate of utilization of health facility for childbirth in rural Chongwe district in Zambia of $42.8 \%$. This rate is higher than the national figure of $27.9 \%$ for rural areas in Zambia. This indicates the large magnitude of variation of health care utilization rate for childbirth between rural districts in Zambia. Compared to other rural areas in the region, our rate is higher than what has been reported in rural Kenya of 5.4\% ${ }^{13}$. However, our finding is comparable with that reported in another study in rural Kenya of $47.5 \%{ }^{14}$, and $37 \%$ reported in rural areas of the Orange Free State in South Africa ${ }^{15}$.

In the current study, place of last childbirth, and knowledge that traditional birth attendants were given none food items (excluding money) were significantly associated with delivering at a health facility.

We found that mothers who reported that TBAs were given none food items (excluding money) after assisting delivery were $45 \%$ less likely to utilize a health facility for childbirth. This finding supports the assertion that it is cheaper for women to be assisted at delivery by TBA than delivery at a health facility in rural areas. However, none food items may be more expensive compared to the cost of delivery at a health facility. In order to convince women in Chongwe district to deliver at a health facility, there is need to compare costs of none food items given to TBAs for delivery assistance and those of delivery at a health facility. A similar study done in rural Kenya ${ }^{14}$ Hodgkin found that the average cost of delivery in health facilities was much higher than for TBAs. Almost half of the TBAs in this rural are in Kenya did not charge their clients, and this may or may not be the case in Chongwe. Even if delivery by TBAs was cheaper in Chongwe, it is important that the quality of delivery services offered by TBAs is evaluated.

The availability of delivery assistance by TBAs has been reported to be associated with non-utilization of a health facility $^{4}$. In communities such as Chongwe that are poorly serviced by health facilities, TBAs will always be used, and there is need to train TBAs in safe delivery, and referral of expectant mothers to health facilities in time to get to the centres. In Chongwe district, Hazemba and Siziya ${ }^{12}$ found that $31.4 \%$ of TBAs were not trained and recommended that more TBAs be trained.

We found that having had last childbirth at home was negatively associated with current delivery at a health facility. This may have been the case when the last delivery at home was complication-free, and mothers would have had a follow-up delivery at home as well. It is important that these mothers are reached when they seek postnatal care services or during clinic outreach sessions and talked to about the importance of delivering children at a health facility despite that they had a previous safe delivery at home. Having had a safe previous delivery is not a guarantee that the follow-up delivery would also be complication-free. To the best of our knowledge, this is the first time a significant association between place of last childbirth and choice of place of current childbirth is being reported.

\section{Limitations of the study}

A number of factors that may confound our findings were not considered in our study such as distance to a health facility, and cultural factors (beliefs and practices). However, we believe these factors may have little influence on our findings that are home-based factors. Our design was a cross sectional study and as with all such studies we can not ascribe causations to the relationships found in the current study, and based on self-report we are not sure whether the respondents may or may not have misreported. However, because the questionnaire was anonymous we have no reason to believe that the respondents may have knowingly misreported in our survey. Our sample was non-random, and as such may not be representative of the target population but may be representative of women attending Under 5 clinics that was our sampled population.

\section{CONCLUSIONS}

The importance of giving birth at a health facility should be communicated to mothers who give birth at home. These can be reached when they attend postnatal services or at mobile clinics. 


\section{ACKNOWLEDGEMENT}

We are grateful to the mothers for their participation in the study. We wish also to express our appreciation to the United States Agency for Development (USAID) for funding the study, and to management for Chongwe District Health Management Team for the permission granted to carry out the study. Lastly but not the least, we are also indebted to Dainess Chinyama for the support she rendered during the period of data collection.

\section{REFERENCES}

1. WHO. Health action in crises. http://www.who.int/ hac/crises/zmb/Zambia.aug05.pdf. Accessed 9 August 2008.

2. Central Statistical Office [Zambia], Central Board of Health [Zambia], ORC Macro. Zambia Demographic and Health Survey 2001-2002. Calverton, Maryland, USA: Central Statistical Office, Central Board of Health, and ORC Macro, 2003.

3. Al-Nahedh NNA. Factors affecting the choice of maternal and child health services in a rural area of Saudi Arabia. Eastern Mediterranean Health Journal 1995;261-9.

4. Esimai OA, Ojo OS, Fasubaa OB. Utilization of approved health facilities for delivery in Ile-Ife, Osun State, Nigeria. Niger J Med 2002;11:177-9.

5. Osubor KM, Fatusi AO, Chiwuzie JC. Maternal health-seeking behavior and associated factors in a rural Nigerian community. Matern Child Health J 2006;159-69.

6. Chowdhury RI, Islam MA, Gulshan J, Chakraborty N. Delivery complications and healthcare-seeking behaviour: the Bangladesh Demographic Health Survey, 1999-2000.
7. Tann CJ, Kizza M, Morison L, Mabey D, Muwanga M, Grosskurth H, Elliot AM. Use of antenatal services and delivery care in Entebbe, Uganda: a community survey. BMC Pregnancy Childbirth 2007 Oct 11;7:23.

8. al-Nasser AN, Bamgbove EA, Abdullah FA. Providing antenatal services in a primary health care system. J Community Health 1994;19:115-23.

9. Kyomuhendo GB.Low use of rural maternity services in Uganda: impact of women's status, traditional beliefs and limited resourcesw. Reprod Health Matters 2003;11:16-26.

10. WHO. Health action in crises. http://www.who.int/ hac/crises/zmb/Zambia.aug05.pdf. Accessed 9 August 2008.

11. Miti SK. The human resources crisis in the health sector in Zambia and efforts by the Ministry of Health to address the crisis. Med J Zambia 2007;34:2-4.

12. Hazemba A, Siziya S. Utilisation of maternal care services offered by traditional birth attendants in Chongwe rural district. Med J Zambia 2007;34:125-9.

13. Cotter K, Hawken M, Temmerman M. Low use of skilled attendants' delivery services in rural Kenya. J Health Popul Nutri 2006;24:467-71.

14. Hodgkin D. Household characteristics affecting where mothers deliver in rural Kenya. Health Econ 1996;5:333-40.

15. Cronje HS, Joubert G, Chapman RD, de Winnaar B, Bam RH. Utilisation of maternity services by black women in rural and urban areas of the Orange Free State. S Afr Med J 1995;85:1190-1. 